\title{
The OECD Blue Book has become a citation classic
}

\author{
Ervin BALÁZS* \\ Department of Applied Genomics, Agricultural Research Institute, H-2462 Martonvásár Brunszvik u 2, Hungary
}

One of the highest accolades a scientist can achieve is to have a paper selected by the Science Citation Index of the Philadelphia Library as the most cited paper of the year. There can be no doubt that the Recombinant DNA Safety Considerations, published by the OECD in 1986 , and known as the Blue Book after the color of the cover, is the resource document most frequently cited at the international level by the various stakeholders of society. I myself, who witnessed and participated in the revolution of molecular biological science and its regulation, have been frequently confronted with this fact: whenever people talk about the introduction of this new technology, the Blue Book is always referred to as the most valuable reference work.

Early on, soon after the two European directives on the contained use of genetically modified organisms and on their deliberate release into the environment were issued (EC 219, EC 220), a steering committee was established for the conservation and management of the environment and natural habitats, in order to study and advise on the potential ecological impact of genetically modified organisms. This committee continued to function until the organization of a Pan-European Conference on the potential long-term ecological impacts of the dissemination of GMOs, all the documents and activities of which used the Blue Book as a major source. As both the developed and the developing world realized the value of biotechnology, regulatory activities were also begun in the US (NIH guidelines) and in other countries, all using this publication as their knowledge base. The conveners of the United Nations Conference on Environment and Development (UNCED) also included biotechnology in its agenda in the document entitled Agenda 21, and devoted a whole chapter to biotechnology (Chapter 16). This chapter and the UNEP International Technical Guidelines for Safety in Biotechnology (printed in all six official languages of the UN) reflect the spirit of the Blue Book. If a comparison is made of the efforts made by individual countries to establish national regulatory frameworks for gene technology, the footprint of the Blue Book is clearly perceptible in each case. Until the year 2000, almost all the industrialized or rapidly

*Corresponding author: balazs@mail.mgki.hu developing countries that introduced gene technology in daily practice had their own separate regulations, while international organizations, such as the Food and Agriculture Organization (FAO), the World Health Organization (WHO) and the United Nations Environmental Program (UNEP), incorporated regulatory issues into their activities, along with the promotion of modern biotechnology. Finally, the Convention on Biological Diversity (CBD) prepared an internationally legally binding document on biosafety, known as the Cartagena Biosafety Protocol. In all these cases, the Blue Book was a major source of information. All the stakeholders at the negotiations, regardless of which sector they represented, cited the OECD Blue Book, as it was written by internationally recognized experts on gene technology, agriculture, environment, ecology and health, in language that was clear even to laymen.

The Blue Book served as a reference text for the international training courses on biosafety initiated by the International Centre for Genetic Engineering and Biotechnology (ICGEB) in Trieste, with the support of UNIDO. These ICGEB training courses are welcomed by the scientific community as well as by national science administrators and regulators. The spirit of the training courses reflects the views expressed in the Recombinant DNA Safety Considerations publication, which also influenced many other publications, some examples of which are:

- Genetically Modified Organisms. A Guide to Biosafety (1995), G. Tzotzos, ed., CAB International, Oxford, $212 \mathrm{p}$.

- Genes on the Menu. Facts for Knowledge Based Decisions (2003), P. Pechan, G.E. de Vries, eds., Spring, $217 \mathrm{p}$

- Genetically Modified Crops. Assessing Biosafety (2002), K.T. Atherton, ed., Taylor and Francis, London, $256 \mathrm{p}$.

- Biosafety and Risk Assessment in Agricultural Biotechnology (2002), P.L. Traynor, R.J. Frederick, M. Koch, eds., MSU East Lansing, 142 p.

The need to harmonize national and regional biosafety regulations is now raised by stakeholders in biotechnology at all international forums. The basis for 
these harmonisation efforts will continue to be the text of the Blue Book.

There can be no question that the Blue Book was also instrumental in initiating biosafety research in academies and universities, making it a priority in EU framework programs, while it also led to very intensive industrial activities. In the light of this research, a number of concerned scientists established the International Society for Biosafety Research (see the society's webpage www.isbr.info, and the paper by J. Schiemann, presented at the workshop).

Twenty years after its publication, the OECD Biosafety Working Group continued to use the terms of reference of the Blue Book when elaborating consensus documents on biosafety risk assessment and management (see the presentation of Gaugitsch at this workshop). Experts on the recently founded European Food Safety Authority's GMO panel use this important document in their daily work (see contribution of J. Schiemann). Today, when over a hundred million hectares are sown to commercial transgenic crops, the safety of this new technology has become an important issue at the society level. From the outset, concern has been expressed over the human health and environmental safety aspects of transgenic crops. It should be noted, however, that the scientists who were responsible for the development of the technology, together with governments and other stakeholders, have taken a proactive approach to theidentification of safety concerns and to addressing them. The first fruit of this proactive approach was the publication of the OECD Blue Book in 1986, the first intergovernmental work on the safety of transgenic crops and other organisms. This was followed by a series of activities at OECD, leading to the elaboration of principles, approaches and practical tools to assist in the risk/safety assessment process.

It is clear from the above that the Blue Book and subsequent publications have become a major resource to the formulation of national regulatory frameworks, and also for intergovernmental activities such as the UNEP Guidelines, the International Plant Protection Convention and the Cartagena Protocol on Biosafety. Since the publication of the Blue Book, new knowledge and technologies have accumulated, and it is time to discuss the impact of this work on modern biotechnology, on regulation and, last but not least, on the acceptance of GMOs by society.

The opinions expressed and arguments employed in this publication are the sole responsibility of the authors and do not necessarily reflect those of the OECD or of the governments of its member countries. The editorial help of Mrs Barbara Harasztos in preparation of this work is highly appreciated. 